\title{
ESTRUCTURAS PARADÓJICAS: As MINAS DE PRATA (ALENCAR) Y MARÍA (ISAACS)*
}

\author{
Paradoxical Structures: As minas DE \\ prata (Alencar) and María (IsaAcs) \\ Juana Maricel Sañudo Caicedo ${ }^{1}$
}

* Artículo derivado del curso Machado de Assis e a Interpretação do Brasil (A Crítica Sociológica de Roberto Schwarz) dictado por el profesor dr. Wilton José Marques, y de sus vínculos con nuestro trabajo doctoral Fisuras, resistencia y movilidad en dos narrativas sobre comunidades imaginadas: María (1867) de Jorge Isaacs (1837-1895) y Afuera crece un mundo (2015) de Adelaida Fernández Ochoa (1957). El presente trabajo fue realizado con el apoyo financiero de la Coordenação de Aperfeiçoamento de Pessoal de Nível Superior de Brasil (CAPEs) - Código de Financiamento 001.

Cómo citar este artículo: Sañudo Caicedo, J. M. (2020). Estructuras paradójicas: As minas de prata (Alencar) y María (Isaacs). Estudios de Literatura Colombiana 47, pp. 93-111. DOI: https://doi.org/10.17533/udea.elc.n47a05

1 https://orcid.org/0000-0003-0438-6353 juana.sanudo@ufscar.br

Universidade Federal de São Carlos, Brasil

Editores: Andrés Vergara Aguirre, Christian Benavides Martínez, Valentina Noreña Gómez

Recibido: 02.02.2020

Aprobado: 09.05.2020

Publicado: 23.06.2020

Copyright: (12020 Estudios de Literatura Colombiana. Este es un artículo de acceso abierto distribuido bajo los términos de la Licencia Creative Commons AtribuciónNo comercial - Compartir igual 4.0 Internacional
Resumen: en el presente estudio se explorarán las relaciones entre la estructura narrativa y la estructura social de las novelas As minas de prata de José de Alencar y Maria de Jorge Isaacs. $\mathrm{El}$ recorte se va a centrar tanto en la estrategia narrativa como en las distintas capas sociales; así, la propuesta permite una estructura dialéctica y paradójica entre las ideas liberales y y la conservación del viejo sistema esclavista representadas en la narración y en la construcción de los personajes, lo que se llamará "ideas fuera de lugar" dentro del proceso de formación de naciones con herencia colonial.

Palabras clave: romanticismo; estructura dialéctica; imaginarios nacionales.

\begin{abstract}
This study will explore the relationships between the narrative structure and the social structure of the novels As minas de prata by José de Alencar and María by Jorge Isaacs. The cut will focus on both the narrative strategy and the different social groups, thus, the proposal allows a dialectic and paradoxical structure between the liberal ideas and the maintenance of the old slave system, both represented in the narrative and in the construction of the characters, what will be called "ideas out of place" within the process of formation as nations with a colonial heritage.
\end{abstract}

Keywords: Romanticism; dialectical structure; national imaginaries. 
As minas de prata (1865-1866) de José de Alencar (1829-1877) y Maria (1867) de Jorge Isaacs (1837-1895) han sido catalogadas como novelas que no se ajustan del todo al modelo de narrativa histórica propuesto por Lukács, según las reflexiones de De Marco (1985) respecto a la obra de Alencar, "constrói um painel das cenas coloniais, mas não recria o movimento da história, composto pela ação de diferentes grupos e interesses. As múltiplas histórias delineiam o caminho de indivíduos debatendo-se com seus conflitos e projetos pessoais" (p. 141). Para el caso de la novela de Isaacs, es Doris Sommer (2004) quien no la enmarca dentro de las novelas nacionales decimonónicas, por considerarla fallida al no mostrar un estado político ideal como, a su juicio, lo hicieron otras obras en Latinoamérica:

El hecho de que la obra culmine trágicamente no es de por sí pesimista, pues otras novelas de la época, entre ellas Francisco (Cuba, 1839), Sab (Cuba, I84I), Amalia (Argentina, I851), Iracema (Brasil, 1865), Aves sin nido (Perú, 1889), y Cumandá (Ecuador, 1879) recurren a la tragedia para animar un programa positivo que evite tragedias por venir. Mientras suscitan nuestra simpatía por los amores entre héroes y heroínas, estas obras también localizan un abuso social que obstaculiza el amor. Por lo tanto, apuntan hacia un estado ideal, tanto político como sentimental, que ha de producirse cuando se supere el obstáculo. De manera implícita, y a veces abierta, esas novelas exigen una solución posible para el romance fallido (léase también para el progreso nacional y la productividad) (s.p.).

Al seguir una perspectiva en la que es posible apreciar la obra de Alencar como el medio en el que se articularon y construyeron ciertas ideas nacionales sobre el Brasil, y de acuerdo con Peres (2015) — ya en relación con el esquema de Lukács, que a nuestro juicio es la lectura más compleja y cercana al punto de vista aquí propuesto frente al caso de Isaacs_- "Assim mesmo não se ajustando inteiramente ao esquema proposto por Lukács —o da figuração da classe média emergente-, As minas de prata não deixa de ser um romance genuinamente contemporâneo de seu momento e espaço históricos específicos” (p. 17).

De modo que es posible afirmar que las obras aquí estudiadas de ambos autores constituyen objetos literarios fundamentales para la comprensión de los imaginarios nacionales en cada país. Ello es comprensible si las ubicamos dentro de esa gran comarca cultural que alguna vez delimitaron tanto Ángel Rama como António Cândido en sus acercamientos a los estudios comparativos latinoamericanos, en los que 
se entiende a la literatura como un cuerpo orgánico "en el cual se expresa una cultura", ya que "el texto literario dialoga con las circunstancias sociohistóricas y culturales de su aparición, generándose así una visión continental que le da a nuestra América una cartografía de índole cultural"(Mejía Toro, 2014,p. 190). Dicha ubicación permite una estructura dialéctica tanto en la narración como en la construcción de los personajes en ambas obras, de lo que vamos a llamar "ideas fuera de lugar" en nuestro proceso de formación como naciones con herencia colonial, siguiendo a Schwarz (2000), ${ }^{1}$ con una conciencia "Impugnada a todo instante pela escravidão a ideologia liberal, que era a das jovens nações emancipadas da América, descarrilhava” (p. 15). En tal sentido apuntan nuestras reflexiones sobre la relación entre hecho externo (nuestras historias de formaciones nacionales) y la estructura interna del corpus escogido. A partir de Cândido (2006), podemos delimitar metodológicamente que "o estudo da função histórico-literária de uma obra só adquire pleno significado quando referido intimamente à sua estrutura, superando-se deste modo o hiato frequentemente aberto entre a investigação histórica e as orientações estéticas” (p. 199).

Hay que señalar, además, que esa lectura dialéctica de la novela como género ya se encontraba en el propio Lukács (2010) cuando refiere las relaciones entre novela e historia durante el Romanticismo, inherentes a su propio proceso de formativo:

La reflexión y el estado de ánimo son elementos constitutivos estructurales de la forma de la novela, pero su significación formal es determinada precisamente por el hecho de que el sistema regulador de ideas en el que se basa la totalidad de la realidad puede manifestarse en ellos y, a través de ellos, adquirir forma; en otras palabras, por el hecho de que se relacionan con el mundo exterior de manera positiva, aunque paradójica y problemática (p. I13).²

Por lo anterior, nuestra lectura dialéctica de estas novelas se centra en una estructura histórica paradojal que anteponía los ideales libertarios propugnados por nuestros próceres en las Independencias, al mismo tiempo que echaba mano de un sistema

1 En ese sentido, se retoma la lectura que hace Schwarz en Ao vencedor as batatas, analizando bajo estas estructuras sociales contradictorias la obra de Machado de Assis. En nuestro caso, la novedad estriba en proponer una historia política y social equiparable en Colombia al analizar la obra de Jorge Isaacs, lectura en la que también se vinculará esta mirada socio crítica con algunos postulados de António Cândido y Georg Lukács. 
esclavista mantenido en la práctica, que en el caso de la Nueva Granada se abolió tempranamente en 1851, mientras que Brasil lo hizo en 1888.

Ahora, el mayor reto será mostrar tal estructura en un recorte que hemos elegido, más por las cuestiones de practicidad y de economía, propias de un artículo. Dicho recorte va a abordar en el análisis tanto la estrategia narrativa en ambas novelas como a los personajes Estácio, Elvira y Joaninha en la obra de Alencar, y a Efraín, María y Nay-Feliciana en el caso de la obra de Isaacs. Paso seguido, se explora a los personajes que componen una constelación de posibilidades de adaptación o exclusión, después de la abolición de la esclavitud, al panorama social: Juan Ángel, el hijo liberto de Nay; Lorenzo, el contrabandista y refugiado en la selva; los bogas Cortico y Laureán, así como Rufina y su padre Bibiano, esclavizados libertos refugiados en San Cipriano y Dagua.

Todo ello, por ser los personajes en los que hay un claro debate, una suerte de dialéctica entre las ideas libertarias de las nacientes repúblicas frente a las ideas más conservadoras y coloniales que continúan en pugna en nuestras naciones.

\section{Una visión móvil entre el plano general y el acercamiento}

Para comenzar, será necesario hacer, aunque de modo esquemático, el análisis narrativo de As minas de prata, para luego pasar a la relación entre la mirada narrativa y la estructura social dialéctica, esa suerte de ideas fuera de lugar que observó Schwarz en su ensayo Ao vencedor as batatas (2000), sobre la gran paradoja brasilera y, a nuestro juicio, latinoamericana, entre las ideas liberales y coloniales.

Pues bien, de entrada en los tres párrafos iniciales de la novela leemos una visión que vamos a llamar "plano general" o de altura frente a la construcción de los espacios e inclusive en la misma elección de unos actores principales de la élite bahiana, como lo son Estácio e Inesita, ambos provenientes de familias que fueron acaudaladas. En el caso de Estácio, porque debido a un error de su padre, al no encontrar las ansiadas minas de plata, le fueron confiscados sus bienes por la corona española-portuguesa, que dominaba en ese momento la colonia brasilera, tiempo histórico de la novela. En el caso de Inesita, en representación de los dueños de ingenios o la clase terrateniente, pues era hija de un gran hacendado. El trecho delimita al menos tres miradas de 
elevación o de altura que nos permiten hacer dichas asociaciones entre estrategia, es decir, mirada inmersa en la estructura narrativa y estructura social paradójica en el siglo XIX, tiempo de construcción de la novela, que mira, sin embargo, al pasado colonial para construir y quizás explicar su presente: "esfolhando a luz serena pelos horizontes puros e diáfanos, dourava o cabeço dos montes que cingem a linda Bahia do Salvador, e desenhava sobre o matiz de opala e púrpura o soberbo panorama da antiga capital do Brasil” (Alencar, 2018 p. 1, énfasis añadido).

La selección de palabras tales como "horizontes", "montes" y "panorama se relacionan con aquello que se eleva, ese lugar desde donde se puede observar todo lo demás, que llegado el caso y dependiendo de la escena, es capaz de bajar la mirada y construir el relato de otras clases sociales, así el enredo central sea propiamente el de la élite. Tal mirada, que va del plano general al acercamiento del detalle, describe una intriga que se basa en varias historias paralelas: la del mundo jesuita y el padre Molina, sus intrigas políticas y la búsqueda del mapa para hallar las codiciadas minas de plata que descubriera el padre del personaje central, Robério Dias, y por cuyo fracaso al intentar dar la ubicación a la corona española y portuguesa es desposeído de sus bienes; la historia de los amores entre las diferentes parejas de la novela, Estácio e Inesita, Cristovão y Elvira, João Fogaça y Mariquinhas, Marina da Pena, esposa de juventud del padre Molina, etc.; la historia de las intrigas políticas y religiosas para apoderarse de las minas de plata, el mundo popular de la bodega de Brás y el mundo de la élite colonial.

En ese orden de ideas, vemos focos narrativos tanto de la élite como de personajes populares a través de toda la obra, lo que es facilitado por la construcción de una novela desde el folletín, con muchos personajes y el largo aliento de tres partes que suman poco más de seiscientas páginas. A continuación, dos fragmentos de los focos narrativos centrados en la élite y en personajes populares:

A fisionomia franca e aberta, as cores frescas e rosadas, o porte firme e direito sobre uma estatura regular, mostravam compleição vigorosa $[\ldots]$ também na Bahia não havia mancebo casquilho como Cristóvão de Garcia de Ávila, senhor de fazenda passante de cinquenta mil cruzados $[\ldots]$.

Um deles era um negro, moço e robusto, cuja tez escura refletia os raios da luz, como o lustro do jacarandá polido. Tinha a feição comprimida peculiar à sua raça: o olhar pesado e torvo; nos lábios grossos, o sorriso carnal da animalidade africana. Com os cotobelos apoiados sobre o arco da quartola acompanhava os 
movimentos do outro. Era esse o taverneiro, o Brás fudengo, como o chamava o vulgo; homem de estatura meã, entre gordo e magro, de cabelo preto corrido e barba ruiva encarapinhada; espécie de ecletismo vivo no moral como no físico; alma anfíbia, habitando no vício tão bem como na virtude (Alencar, 2018, pp. 4-5, 43-44, énfasis añadido).

Si bien encontramos esas dos tendencias narrativas de ascenso y descenso en la escala social, las descripciones de ambos cuadros son diferenciadas, pues tenemos que en el caso de Cristovão y Estácio, sus ropajes y alcurnia son equiparables a sus virtudes, comparados con los calificativos casi naturalistas de los personajes que se encuentran en la taberna del judío Brás, un afrodescendiente adjetivado desde lo animalesco, y el propio judío como alguien igual de monstruoso que su compañero. En ese sentido y siguiendo a Marczyk (2006), quien analiza la figura de los judíos como caótica y cambiante, quizás la de Brás, al ser traficante, encarna esas características indeseables para lo que va a ser la nación brasilera, a diferencia de Elvira, pues al unirse a Cristovão, aunque fuese en pecado desde la estructura religiosa de ese mundo decimonónico, sí puede ser absorbida por el pueblo brasilero:

[...] constitui uma forma de representar a imagem judaica caracterizada pelo desequilíbrio e a monstruosidade. Joaquim Brás, ou Brás Judengo, enquanto personagem de ficção, não pode ter sua imagem investigada a ponto de sabermos se realmente pertence à linhagem de Abraão visto que a composição do romance o faz como uma entidade limiar, em estado de indefinição, tipicamente exterminável em um contexto que se empenha em substancializar traços de identidade - da nação e do homem nacional — , por definição, opostos a tudo que o dito personagem representa [...]. Elvira representa e reapresenta, em um texto que intenciona construir a imagem da origem do povo brasileiro, o arquétipo feminino projetado no Gênesis bíblico. Ao ser nomeada, ganhou por força da nomeação, uma identificação da mulher edênica, Eva [...]. Desse mesmo modo, ainda que o romance dê vida a outros personagens estrangeiros - holandeses e espanhóis - que são negados, expulsos e execrados, eles não se prestam a preencher os traçados da origem da nação brasileira (pp. 66, 75, 89-90).

Resulta entonces definitoria la capacidad del narrador para mostrar el proyecto pacificador del Estado-nación a través de las trayectorias de movimientos de la élite o de movimientos populares en la novela en sus focos narrativos. También se nota esa tensión desde las adjetivaciones de los personajes, cuando son focalizados dependiendo de su proveniencia social, lo que tejería ese proyecto de nación paradójico — que une 
linajes para construir una identidad homogénea, al tiempo que rechaza o acepta con dificultad todo lo que quepa en ello- propio del siglo xIx, entre las ideas libertarias de lo que sería Brasil, frente a esa sombra de la esclavitud todavía presente mucho después de su independencia. Resta analizar el caso de los personajes escogidos para continuar en la dialéctica de tales ideas fuera de lugar.

\title{
El doble movimiento entre el idealismo europeo vs. realidad colonial
}

En lo que se refiere a los personajes del corpus estudiado, son representativos los casos de Estácio, Elvira y Joaninha, particularmente, porque presentan una dialéctica de las ideas fuera de lugar en la obra, además de la tensión entre lo que serían las ideas libertarias, frente a la manutención del sistema esclavista hasta casi finales del siglo xIx. Así, en cada uno de estos personajes hay un movimiento doble: el idealismo frente a la realidad colonial.

En el caso de Estácio, como lo menciona Peres (2015), hay dos figuras simbólicas en la formación del héroe, ambas en tensión subterránea de lo que fuese un dilema político en la formación de la nacionalidad brasileña:

\begin{abstract}
Vaz Caminhaépor excelência “O homem dajustiça, vir probus". Tendo praticamente criado Estácio, Vaz Caminha o vê "como um outro eu". Mas Estácio - herói de capa e espada repuxado entre duas linhas quase opostas de proceder que trazem em seu bojo dois projetos civilizatórios distintos - sente um mal-estar em relação a seu mestre quando este incorpora justamente o homem da lei [...]. A resistência do jovem revela o lado simetricamente oposto de sua formação, representado na figura de Álvaro de Carvalho, legítimo herdeiro dos cavaleiros medievais para quem a honra é o valor último, a qual é defendida na ponta da espada (pp. 56-57).
\end{abstract}

Desde nuestra lectura, esa cara doble en la formación del héroe se debe a la dialéctica de las ideas liberales frente a las posturas más conservadoras en la formación del Brasil durante el siglo XIX, o la pugna entre el idealismo y la realidad colonial persistente.

En lo que respecta al personaje Elvira, el dualismo se va a representar a través del hecho de ser judía por sangre, aunque cristiana en su formación y prácticas. Así y a diferencia de la judía conversa que muere en María, Elvira, al unirse a un heredero portugués, Cristovão Garcia de Ávila, y tener un hijo, ya plenamente brasilero y 
con las dos sangres, recupera el lugar de la alteridad judía para la formación de la nacionalidad brasilera. Final distinto a otros judíos que aparecen en la obra, como Brás, Samuel, Raquel y la misma Luisa, madre de Elvira, quienes por contravenir la ley o ser descritos sin virtudes posibles no entrarían en las comunidades imaginadas para el constructo nacional. De modo que la dialéctica entre tales ideas, de lo extraño/ extranjero frente al ideal de nacionalidad lusitano, estas se estarían fundiendo para dar lugar a un tercer tipo, el hijo de Elvira y Cristovão, aunque su rechazo por el asunto de la pureza de la sangre y el camino dificultoso de esta pareja describiría la tensión constante y no del todo feliz durante la Colonia.

En esa misma línea argumentativa, de las identidades que parecen no ajustarse al imaginario del Estado-nación ideal, más allá del lusitano, entra el tema de los personajes africanos o afrodescendientes en la obra. El primer personaje descrito en la taberna de Brás es adjetivado de manera "animalesca”, es decir, contravendría ese ideal nacional, además de notarse el espinoso asunto de la esclavitud que culmina solo en los albores de la República brasilera. Asunto que es notorio en la caza de esclavos fugitivos que hacen tanto Brás como João Fogaça, como se menciona en la historia del "capitán del bosque": "Era quem melhor policiava o estado, e ia aos desertos e sertões trazer o réu à justiça, o escravo ao senhor, e perseguir as hordas selvagens quando infestavam a vizinhança dos povoados" (Alencar, 2018, p. 160)

No obstante, hay un personaje afrodescendiente, Joaninha, vendedora de plaza, quien no es descrita de manera negativa, aun en esta pugna de imaginarios coloniales. Antes bien, son resaltadas sus virtudes, sus proezas para sobrevivir, su dignidad e incluso sus habilidades para tejer historias y para ayudar a la pareja de personajes principales, Estácio e Inesita: “mas Joaninha, que já tinha ganho pela formosura e jovialidade a admiração geral, ganhou com uma virtude austera e uma esquivança constante, a estima e respeito da boa gente" (Alencar, 2018, p. 107).

A nuestro modo de ver, este personaje sería equiparable, aun teniendo en cuenta la aparente armonía del proyecto pacificador nacional, también dentro de la novela de Isaacs, que se analizará en la segunda parte del escrito, con la esclavizada liberta Nay-Feliciana, pues a pesar de todo, hay una suerte de mirada preliminar que rescata, aunque sea desde la fisura, el papel de los aportes de lo negro africano, desde ese pasado histórico difícil de la construcción de los imaginarios en nuestras naciones. 
De manera que concordamos con Peres al ver al personaje como un puente entre las clases sociales, y al hacerlo entrar, ya de manera temprana y como fisura en las nuevas nacionalidades:

\begin{abstract}
Nessa interação subliminar entre a dozela e a alfeloeira, a agulha de Inês (que bordava na sala enquanto tentava abafar sua aflição) funciona como metonímia da narrativa de duplo sentido da história dentro da história que é tecida por Joaninha -é esta verdadeiramente que conduz as emoções de todos os presentes na sala da casa grande. Este episódio de Joaninha na casa dos Aguilar parece remeter à própria infância de Alencar, quando o então menino precoce é aluno aplicado lia à luz do candeeiro na "sala do fundo", onde "minha mãe e minha tia se ocupavam com trabalhos de costura, e as amigas para não ficar ociosas as ajudavam". Benjamin, em seu ensaio seminal, diz, que "o grande narrador se enraizara sempre no povo, antes de mais nada nas suas camadas artesanais" (Alencar, 2018, pp. 87-88).
\end{abstract}

Siendo entonces ese narrador en tercera persona el artífice de un doble movimiento, focalizándose en las élites y al tiempo en las clases populares, es particular e interesante el caso de Joaninha, que además parece ser un alter ego del propio narrador, por ese juego de contar una historia dentro de la historia. Algo similar vamos a encontrar en Nay-Feliciana, ya que también Efraín, el narrador de María, va a remitirnos a la historia contada mil veces por la anciana, de su relato sobre la diáspora africana y la trata esclavista hasta llegar a la Nueva Granada. Podríamos pensar también, como lo sugiere Peres (2015) al mencionar la infancia de Alencar, en la propia infancia de Isaacs y en los relatos que recibió de su aya Isidora, una de sus fuentes para crear al personaje de la esclavizada liberta.

En consecuencia,la imagen que nos devuelvela obra de Alencar es una representación de las complejas relaciones, pactos, tragedias y negociaciones raciales que se hicieron durante ese fundante siglo XIX, su legado en torno a las nacionalidades que heredamos y que nos urge seguir leyendo, comprendiendo y transformando, a fin de ir más allá de ese aparente "proyecto pacificador" del Brasil, que le discute el autor a la crítica Doris Sommer (Peres, 2015, p. 105) y que también discutimos en el caso de Isaacs.

Finalmente, podemos afirmar que Alencar logró mostrar, en la tensión entre la estructura dialéctica de su narrativa y la vocación doble de sus personajes, las ideas fuera de lugar en la constitución de sus imaginarios nacionales, divididos entre las ideas 
más liberales y el sistema esclavista, como efectivamente aconteció a lo largo del siglo XIX, pues "Nenhuma das reformas que os liberais realizaram eliminou o conflito entre a retórica liberal e o sistema de patronagem. As reformas defendiam apenas os seus interesses comerciais e a manutenção da exploração do trabalho”(Pereira Lage, 2006).

\section{Hacia una estructura de la nostalgiay de la ruina o del paraíso perdido de Efraín}

Ahora bien, en el caso de Maria, la obra del escritor colombiano Jorge Isaacs, las estructuras o contextos sociales decimonónicos también reflejan la tensión entre las ideas liberales, así como el gradual, violento y paradójico desmonte de la estructura esclavista en la Nueva Granada. Por ello se hace necesario revisar la temprana abolición legal de la esclavitud en este país, con todas sus demoras y contradicciones en la implementación de esta realidad y en la inclusión patente de los manumisos en el proyecto de nación, a fin de comprender la estructura narrativa de la obra. En ese mismo orden de ideas, aparece la vocación doble de sus personajes, como es el caso de Efraín, equiparable por su duplicidad a Estácio; María, equiparable por su origen judío y su inserción problemática en las ideas de la nación colombiana, como lo fue el caso de Elvira en As minas de prata. Finalmente, los personajes Nay-Feliciana, esclavizada manumisa que trae la historia de la diáspora africana dentro de la gran historia de la novela, equiparada a Joaninha, la mulata y artesana, que también inscribe otra historia dentro de la historia en la obra de Alencar, cual puente entre diferentes clases sociales.

A fin de comprender esa tensión, esa suerte de ideas fuera de lugar entre los imaginarios liberales y la manutención de un régimen patronal, que también se dieron en la Nueva Granada, es necesario revisar en dos momentos esta historia nacional en torno a dicha duplicidad; el primero, alrededor de las imágenes sobre la abolición, como sus consecuencias prácticas, y el segundo, al reflexionar sobre el modelo de abolición que adoptamos, definitorio en nuestro proceso de construcción de nacionalidad. Sobre el primer momento, mucho nos iluminan las historias nacionales, pues ellas

[...] suelen presentar ese paso hacia la libertad generalizada de los esclavos, como una transición apacible y sucesiva de actos que pusieron fin a la institución esclavista, gracias a la filantropía de los Estados. En el caso de las repúblicas que emergieron de la escisión del imperio hispánico, los relatos de las Independencias suelen velar la complejidad del proceso que condujo a la abolición definitiva de 
la esclavitud y la multiplicidad de eventos, instituciones y actores que se incorporaron al mismo [...]. Los procesos penales y civiles que se siguieron desde finales de la Colonia cuentan con la presencia de los esclavos y permiten hacer seguimiento de sus actuaciones, específicamente de sus resistencias, que fueron perseguidas por autoridades coloniales y criminalizadas en tiempos republicanos (Cuevas, 2018, pp. 4, 7, énfasis añadido).

Dos hechos serán importantes en el análisis del primer momento, cara a la interpretación que haremos de la obra artística. El primero tiene que ver con cómo tejieron las historias nacionales, hemos de decir, nuestra historia nacional, la abolición en tanto transición apacible. En María dicha idea aparece como patente en ese idílico mundo de una transición feliz, motivo por el cual una parte de la crítica, señalando el caso de Doris Sommer (2004), no la considera una novela de corte nacional, justo por la ausencia de un contexto histórico complejo. El segundo hecho crucial es entender que la abolición no significó un cambio estructural en las relaciones sociales, aunque claro, fue el comienzo de implicaciones políticas y sociales de largo aliento, no sin antes producir, justo por esa ausencia de una mudanza estructural, procesos de exclusión de los africanos y afrodescendientes. Los dos hechos se acompañan dentro de la paradoja vivida también en Brasil, esa duplicidad entre ideales liberales y, al tiempo, los rezagos de un sistema esclavista presente en las naciones en construcción.

En el segundo momento de la historia, la reflexión sobre el modelo de abolición adoptado en el contexto de la Nueva Granada será clave, ya que la gradualidad — retomada del modelo anglosajón—, su progresividad y "solución intermedia” eran más un acicate para los amos, aunque se vendiera la idea de la necesidad de preparar para la libertad a los esclavizados que, más que gradualidad, en realidad necesitaban de una estructura no solo legal, sino económica que los insertara en la nación. Se trataba de una cuestión que comenzaba con los imaginarios y terminaba en la economía:

La abolición seguida bajo el modelo anglosajón se caracterizó porla gradualidad. Aunque este tipo de abolición se realizó de manera exitosa y completa en las colonias británicas del Caribe (entre I833 y I840), su origen data de finales del siglo xviıI, cuando se iniciaron una serie de debates en torno a la abolición de la esclavitud, en el marco de la Revolución norteamericana. Una vez establecido el régimen federal de los Estados Unidos de América, se retomó el debate abolicionista, sin 
que este constituyera un tema central en la construcción de la nueva república. Los estados del centro y norte del país llevaron a cabo discusiones legislativas en las que terminó por acogerse un modelo de abolición progresiva de la esclavitud. De esta forma, emergió la propuesta de la gradualidad para llevar a cabo la abolición de la esclavitud y como solución intermedia que permitía respetar los derechos de propiedad de los amos y preparar - en teoría - a los esclavos, para convertirse en persona libres (Cuevas, 2018, p. 9, énfasis añadido).

Con todo, ese fue el modelo asumido por nuestra joven nación, que se vanaglorió de la temprana abolición y de emular ideales franceses, aunque su modelo inspirador haya sido anglosajón. He ahí nuestra tensión histórica y la duplicidad frente a los imaginarios en la construcción de las ideas sobre la nacionalidad, la tensión entre el liberalismo y la presencia del sistema patronal. Una razón de carácter económico para favorecer a los terratenientes y dueños de esclavos. Sin duda, Isaacs estructura dicho sistema paradojal en su obra. Es por tal razón que, al leer sus páginas, encontramos escenas bucólicas de remembranza de la esclavitud con las haciendas del padre y su cohorte de esclavizados, manumisos, cimarrones, irlandeses contrabandistas de materias primas y de esclavizados, pese a la prohibición de la trata transatlántica, etc.; todo un mundo de la trata que se resistía a desaparecer, pero que por las mismas leyes frente a la esclavitud tenía la condición de otorgar la libertad de manera "gradual" y de “solución intermedia”. A pesar de este contexto, no podemos olvidar el paso político del conservadurismo al liberalismo del autor, quien además, y pese a que en su obra representa la enorme influencia del cristianismo en el siglo xix, fue un defensor de la separación entre Estado e Iglesia, e incluso en la primera versión de la novela (1867, imprenta de Gaitán) escribe en una nota a pie de página al final del relato de Nay sobre la diáspora africana, una crítica a la Iglesia y su complicidad en la trata esclavista, nota que señala María Teresa Cristina (2005). ${ }^{3}$ Ante tal dicotomí, ¿a quién hemos de escuchar al fin?, ‘al conservador de la primera etapa o al liberal que escribió dicha nota, la cual habría de ser retirada a partir de la tercera edición de su obra? En cualquier caso, vamos a quedarnos con la voz de la obra, vale decir, la voz del narrador que indicará ambas caras de la moneda para comprender el panorama complejo del siglo XIx en la Nueva Granada y las vicisitudes de las nacionalidades allí envueltas. actividades no le dejaron mucho tiempo para ello. Pero una de estas es muy significativa: la supresión de la parte final de la nota del capítulo xuIv acerca del papel que desempeñó la Iglesia en relación con la esclavitud”(p. 29). 
De ese modo, Efraín, narrador y personaje de María, nos muestra en un primer movimiento el narrativo, y más tarde, en la presentación de personajes como María y la esclava manumisa Nay, la dialéctica de lo que fue nuestro proceso de construcción de nación, las ideas fuera de lugar, al héroe entre el idealismo y la contingencia de ser hijo de un señor esclavista.

Pues bien, la estructura narrativa de la novela, que hemos definido como estructura de la nostalgia, de la ruina y anhelo de un locus amoenus o paraíso perdido de la esclavitud, replica esa otra estructura asumida durante el proceso, e incluso en la posteridad de la abolición. Narrativamente hablando, la obra se constituye en tres momentos narrativos: la retrospección a la partida de Efraín hacia un colegio de la capital; el retorno al hogar junto al reconocimiento del mundo esclavista en las haciendas del padre y la historia de amor con María, seguida de la desdichada partida a Londres a fin de estudiar medicina ante el futuro de las haciendas que no parece promisorio, y por último el regreso, en el cual tanto la amada como el mundo bucólico del esclavismo aparecen en ruinas, y en el que se augura un futuro bastante gris en la historia personal del protagonista y del contexto en el que está inmerso.

Podríamos decir que el primer tiempo narrativo ya vaticina esa prospección aciaga de la muerte de María y de la ruina del locus amoenus de la esclavitud. En el segundo momento, el presentificado y más largo de todos, donde prácticamente acontece toda la acción, se vive la estructura de la nostalgia, del locus amoenus hecho carne en María, en la casa paterna, en las haciendas y en los esclavizados, algunos de ellos manumisos que, sin embargo, seguían ejerciendo el mismo rol. El ejemplo más patente de ello es Nay, quien es manumisa antes de llegar a la casa de la Sierra, y que muere sin mudar mucho su condición. Frente a esos dos primeros momentos, el tiempo prospectivo del final de la obra es el más corto y, sin embargo, el más problemático por ser abierto, lo que esquematiza el mismo sentido de la ley de "gradualidad" asumida frente a la trata.

Para culminar este breve análisis estructural y siguiendo con el realce que ya dimos a la voz narrativa en tercera persona en la obra de Alencar, que muestra varias historias intercaladas en un ascenso y descenso sobre diferentes capas sociales, vamos a esquematizar la postura del narrador y de las historias intercaladas 
en la obra de Isaacs. Como ya hemos mencionado, Efraín, hijo de un hacendado del interior del Cauca, es el narrador y personaje central de una novela que, a pesar de lo reducida que puede ser la estrategia de un narrador homodiegético y de la desconfianza que podemos tener frente a su discurso subjetivista, logra navegar por varias capas sociales y raciales del contexto neogranadino. Así, en nuestro esquema de las secuencias, con las historias intercaladas en María, diferenciamos nueve de ellas con varias historias secundarias, a saber: la que inicia con la retrospección hacia el primer viaje a Bogotá, que aleja a Efraín del hogar paterno; la que introduce las historias de los judíos y afrodescendientes en general - la historia de María y de sus padres Sara y Salomón; la de Pedro, el esclavizado que contaba historias en la infancia de Efraín; la mención a Higinio, el mayordomo; la del matrimonio de Bruna y Remigio, esclavizados de una de las haciendas del padre; la de Julián, el capitán de la cuadrilla, y la alusión a los "agregados y esclavizados manumisos" (Isaacs, 1957, p. 14)—; la que presenta a Emigdio y a Carlos, amigos de estudio en Bogotá del protagonista, y de paso introduce el ambiente de la metrópoli; la que exhibe una cacería en la que aparece por primera vez Juan Ángel, el hijo de Nay; la que presenta a Tránsito, su padre José y su enamorado Braulio, campesinos de Antioquia y amigos de la familia de Efraín; la que describe el relato de la diáspora africana en la novela, una de las secuencias más largas y que merece especial detenimiento, pues abarca la enfermedad, muerte y rememoración de las historias de infancia que le escuchaba el narrador a Feliciana, una de las esclavizadas de la haciendo Santa ${ }^{* * *} ; 4$ la que relata los preparativos del viaje de Efraín hacia Londres, y en la que se narra la historia intercalada de los amores entre Salomé y Tiburcio, amigos de Efraín; la que muestra a Efraín partiendo de Londres y en su viaje hasta la Nueva Granada tras recibir una

4 El relato nos remite a la historia de Nay (nombre original de Feliciana) como princesa Achanti, hija de un distinguido jefe de estos ejércitos, Magmahú, y quien se enamora de un siervo de su padre, Sinar, con el que se casará, después de muchas peripecias, por medio del ritual cristiano que un sacerdote francés oficia en su misión evangelizadora en las costas africanas. Luego vemos cómo los Kombu-Manez son atacados por los Cambez para ser vendidos y embarcados en navíos que llevarán a Nay y a Sinar — pues Magmahú ha muerto- hasta Cuba y de ahí a costas del Darién en la Nueva Granada. Durante el viaje, Nay pierde de vista a Sinar y cuando llega al país de Efraín lleva en su vientre el hijo de este amor. Tras las amenazas de la esclavizada por abortar o suicidarse, el padre de Efraín la compra a Sardick, un contrabandista irlandés, y aunque le da una carta de manumisión, se la lleva a la casa de la Sierra para servir a su familia. Esta secuencia finaliza con la vuelta al tiempo presente de Efraín, el velorio y la pregunta sobre el futuro de Juan Ángel, hijo de Nay-Feliciana, quien bajo la ley de vientres es libre en el país, pero después de unos años más al servicio como criado del padre de Efraín. 
carta que cuenta sobre la enfermedad de María ${ }^{5}$ y por último la secuencia en la que Efraín regresa a la casa de la Sierra, para despedirse de sus recuerdos amorosos de María y de la hacienda, y finalmente cerrar la novela con su vuelta a la ciudad.

El anterior esquema secuencial y de historias intercaladas da cuenta de la maestría estructural y su planeación cuidadosa, al insertar distintos tipos sociales y étnicos, además de territorios culturales diversos en la trama: vamos desde el interior del Cauca, hasta la selva entre Buenaventura y Cali, pasamos por Antioquia y la metrópoli bogotana. Por lo que reafirmamos, como en el caso de As minas de prata de Alencar, esa amplitud del foco narrativo para ascender y descender en distintos tipos sociales y culturales. En ambos casos, podríamos leer ese proyecto pacificador del Estado-nación, no obstante, en la construcción de personajes, las paradojas y contradicciones frente a este modelo serán notorias.

\section{Duplicidad en Efraín, fragmentación en María y Nay: dos mitades de un espejo roto}

En nuestro análisis de personajes vamos a privilegiar tres entradas: la primera va a centrarse en la figura dual de esas ideas fuera de lugar en Efraín, que se encuentra entre el discurso del padre y sus ideas libertarias sobre la nación. La segunda, en Nay-Feliciana y María como las dos mitades del espejo roto de la nación frente a otras razas y posiciones de género o sociales en la construcción de la nación neogranadina. Por último, la tercera entrada va a explorar personajes que en apariencia no son importantes en la obra, por aparecer por breves momentos, pero que componen una constelación de posibilidades de adaptación o exclusión, después de la abolición, sobre el panorama social del país. Para empezar y, en el caso de Efraín, al igual que en el de Estácio, hay una división entre dos proyectos civilizatorios: el que autoriza la voz del padre, señor de ingenio, y las ideas liberales que apoyaban la consecución de la ley contra la trata. Una conciencia de las leyes que, aunque parece venir del padre al comprar y libertar a Nay-Feliciana, en realidad relata un discurso, mientras actúa como la mayor parte de los hacendados,

5 Esta secuencia también es una de las más largas, debido a que describe su partida de Londres, pasando por el mar de la India, Panamá y, más detenidamente, la llegada a Buenaventura, Dagua, San Cipriano, E1 Salto y Las Cruces. En estos lugares se encuentra con dos bogas, Cortico y Laureán, a Rufina y su padre Bibiano, afrodescendientes libertos, y a Lorenzo, liberto y presuntamente contrabandista, que está confinado en la espesura de la selva entre Buenaventura y Cali. Al llegar a su destino final que es la casa de la Sierra, en donde ya no está la familia, ya que María ha muerto, el héroe debe ir hasta Cali. 
manteniendo lo que ellos consideraban sus "propiedades", hasta que el Estado pagase una indemnización o hasta cobrarla con el mismo trabajo sustentado en la servidumbre de los propios esclavizados, parcialmente libres después de la ley de vientres. Aquí cabe pensar en el caso concreto de Juan Ángel, quien continuará siendo un esclavizado después de su mayoría de edad: "Mi padre le hizo saber que era completamente libre, aunque la ley lo pusiese bajo su cuidado por algunos años, y en adelante debía considerarse solamente como un criado de nuestra casa” (Isaacs, 1957, p. 170). De manera que el personaje, al igual que su madre, tendrá que seguir cargando con el peso de la esclavización como lo hizo Nay, quien murió siendo sierva de la familia y en vida se debatió entre escapar de aquella tierra que no le brindó la libertad, a pesar del paraíso que ve Efraín en ella, y la plena consciencia de la suerte de Juan Ángel dadas las leyes del país.

En cuanto a la segunda entrada de análisis, esa exclusión de lo otro, vista en los casos de los destinos aciagos tanto de María, judía, como de Nay-Feliciana, africana y esclavizada, nos enseña dos mitades del espejo roto de la nacionalidad neogranadina que se estaba construyendo, una nacionalidad basada en la exclusión sistemática del otro, donde las muertes de María y Nay constituyen símbolos de la imposibilidad de asumir la diferencia. Una realidad que nos corresponde revisar hasta nuestros días.

Con todo, Nay y su historia en el gran relato de la novela remiten al juego de la caja china, una historia dentro de la historia, es decir, inclusión y tensión entre la trata esclavista y la libertad, entre una esclavizada y su vida como sierva, a pesar de la carta de manumisión que obtuvo ni bien pisó tierras americanas (p. 166). Doblez. Abolicionismo gradual. Transición apacible. Y, entre tanto, la Nueva Granada se incendiaba en guerras de conservadores terratenientes que no querían perder sus “inversiones”, mientras los liberales seguían el juego del mercado inglés; al mismo tiempo, los africanos y afrodescendientes resistían en guerras propias y ajenas o se exiliaban fuera de las metrópolis para huir de una ley que les prometió mucho desde la Independencia, pero les cumplió poco a poco. Libertad a cuentagotas.

Finalmente, tenemos el caso de personajes poco estudiados en la obra como Lorenzo, Cortico, Laureán, Rufina y Bibiano. A pesar de ser narrados por esa mirada nostálgica, patriarcal y desde el proyecto pacificador del Estado-nación, esquematizan representaciones de la ley de vientres y su incertidumbre de cara al proceso abolicionista, así como las resistencias de los libertos fuera del espacio de las metrópolis, pues "se 
internaban en zonas selváticas donde construían sociedades en muchos aspectos autosuficientes, con referentes comunes propios que partían de cuestionar los referentes comunes a la sociedad criollo-mestiza” (Cruz Rodríguez, 2008, p. 67). Así, los casos del contrabandista Lorenzo, quien prefiere vivir en la periferia en donde "las gentes porteñas le parecían cada vez más alegres, comunicativas y despreocupadas [...] después de algunos meses de permanencia en la costa" (Isaacs, 1957, p. 216) y de los bogas, remeros de ríos, que pueden expresar sus cantos (p. 220) pese al ojo vigilante de la Colonia, como también la vida fuera de los centros de poder de Rufina y su padre Bibiano, quien "Había sido esclavo hasta los treinta años en la mina de Iró, y a esa edad consiguió a fuerza de penosos trabajos y de economía comprar su libertad y la de su mujer, que había sobrevivido poco tiempo a su establecimiento en el Dagua” (p. 226).

El exilio interno en esas zonas selváticas era una suerte de resistencia a una libertad que no significaba demasiado y que se representa a cabalidad en la obra. Límites imprecisos como el caso de Juan Ángel, hijo de una esclavizada y manumiso por la ley de vientres en la Nueva Granada. La espera por la libertad será larga y plagada de incertidumbres, de dudas como las que acompañan a Nay hasta su lecho de muerte. Por ese mismo motivo, Juan Ángel insiste en la posibilidad de viajar con Efraín a Londres: "el negrito, que ya tenía noticia de mi próximo viaje, manifestó que lo único que deseaba era que le permitieran acompañarme, y mi padre le dio alguna esperanza de complacerlo" (p. 170), como última alternativa para escapar de un país en donde no le significaba mayor mudanza la tan ansiada libertad:

Las pugnas por la abolición definitiva en 18 r t tuvieron la fuerza suficiente para degenerar en el levantamiento de los esclavistas caucanos. Aunque la victoria liberal aseguró formalmente la libertad de los que antes habían sido esclavos, las formas de servidumbre y administración privada de esta población persistirían y los negros accederían a una ciudadanía de forma tutelada, supeditados a quienes supuestamente les habían otorgado ese derecho (Cruz Rodríguez, 2008, p. 7I).

Como pudimos notar en la escena final entre el padre de Efraín y Juan Ángel, a este aún le restaban algunos años de servidumbre en la casa de la Sierra, así que se trataba de una forma de ciudadanía incompleta, tutelada y en búsqueda de suministrar las mayores ganancias a los hacendados antes de que cayera del todo el sistema esclavista. 
Un último tema, no menos importante, es la posición de la Iglesia en ambas obras, pues en el caso de Alencar, hay una fuerte crítica hacia la Compañía de Jesús, representada en el maquiavélico padre Molina. Ocurre algo similar en María y la postura crítica ante el cristianismo evidenciada en la mencionada nota de la primera edición:

\begin{abstract}
Si hay quien pueda creer exageradas las desventuras de Nay y de sus compañeros de esclavitud, la lectura del capítulo vi, época xiv, 7 del xviI, bastará á convencerle que al bosquejar algunos cuadros Época xvin de la Historia universal de Cantú del episodio no han desdeñado tintas que podían hacerla parecer espantosamente verdadera, y se persuadirá además de que el Catolicismo ha sido el perseguidor tenaz y realmente desinteresado que la esclavitud ha tenido desde Pio xII (I462) hasta hoy (Isaacs, 1867, p. 206).
\end{abstract}

Tras granjearse muchos enemigos — debido a que se asumió como liberal y luchó por un Estado laico a riesgo incluso de ser excomulgado- y sufrir muchas derrotas económicas, políticas e incluso personales, es posible que Jorge Isaacs decidiera retirar la nota a partir de la tercera edición, quizás con el ánimo de no cerrar el camino al éxito de su obra, éxito que no tuvo él mismo. De acuerdo con Cristina (2017), "Esta conversión al radicalismo no le fue perdonada por muchos de sus antiguos copartidarios; le valió rencores y burlas hasta el final de su vida" (párr. 12).

Como epílogo, y si pensamos en la estructura general de María, ella inicia y cierra con una partida. Recalcamos el uso del locus amoenus o el paraíso perdido del mundo esclavista de las haciendas, que se resquebrajaba en la Nueva Granada. No obstante, el abandono de ese mundo bucólico mantenido para privilegiar a los señores de ingenio, del que hacía parte el héroe, constituía una tragedia para el personaje; se trataba de la caída de un sistema de valores que formaban el mundo conocido para este tipo social y, por ello, de la estructura social de esa tensión entre las ideas liberales y el viejo sistema patronal que recorrió el siglo xix tanto en Brasil como en la Nueva Granada. La historia había hablado, el tiempo de los terratenientes estaba terminando; quizás tal sea el sentido profundo, en la obra de Isaacs, de la romántica partida a caballo mientras caía la noche, y el escape de los enamorados Inesita y Estácio a un lugar que no fuese la ciudad de Salvador, es decir, la vuelta al locus amoenus. Como vemos, se trata entonces de estructuras de la ruina, cíclicas, que giran incesantemente sobre sí mismas. 


\section{Referencias bibliográficas}

Alencar, J. (2018). As minas de prata. Rio de Janeiro: Garnier. Recuperado de: https://bit.ly/2XY4xrU [01.06.2019].

Cândido, A. (2006). Literatura e Sociedade. Rio de Janeiro: Ouro sobre azul. Recuperado de: https://bit. 1y/2Y5aYK5 [02.04.2019].

Cristina, M. T. (2017). Jorge Isaacs Ferrer. Recuperado de: https://bit.ly/2MV2QoL [22.07.2019].

Cristina, M. T. (2005). Introducción. En J. Isaacs. María. Obras completas Jorge Isaacs. Volumen I. (pp. 21-36). Bogotá: Universidad Externado de Colombia - Universidad del Valle. Recuperado de: https://bit.ly/3hqpYJW [22.07.2019].

Cruz Rodríguez, E. (2008). La abolición de la esclavitud y la formación de lo público político en Colombia 1821-1851. Revista Mem.soc 12 (25), pp. 57-75. Recuperado de: https://bit.ly/3fqICzo [22.07.2019].

Cuevas, M. F. (2018). El proceso de la abolición de la esclavitud en la Nueva Granada (1780-1860). Tiempos y contratiempos de una transición significativa, entre la Revolución y la República, Nuevo Mundo Mundos Nuevos (Tesis doctoral). París: eness. DOI: https://doi.org/10.4000/ nuevomundo.72382 [22.07.2019].

De Marco, V. (1985). As minas de prata: O rosto brasileiro. Revista V. Lingua e Literatura 14, pp. 125-142. Recuperado de: https://bit.ly/2Y0iLIZ [22.07. 2019].

Isaacs, J. (1867). María. Bogotá: Imprenta de Gaitán.

Isaacs, J. (1957). María. Argentina: Editorial Sopena.

Lukács, G. (2010). Teoría de la novela. Un ensayo histórico filosófico sobre las formas de la gran literatura épica. Argentina: Ediciones Godot.

Marczyk, M. B. F. A. (2006). Representações cristãs do povo judeu em As minas de prata, de José de Alencar (Dissertação de mestrado), Universidade de São Paulo, Departamento de Letras Orientais da Faculdade de Filosofia, SP. Recuperado de: https://bit.ly/37xNAbc [22.07.2019].

Mejía Toro, E. A. (2014). Ángel Rama y Antonio Cándido: la integración del Brasil en el sistema literario latinoamericano. Literatura: teoría, historia, crítica 16 (1), pp. 165-192. Recuperado de: https://bit.ly/30GQCII[02.06.2018].

Pereira Lage,A.C. (2006). Liberalismo no Brasil. Navegando na História da Educação brasileira. Histedbr - Faculdade de Educação - unicAmp. Recuperado de: https://bit.ly/2UKVgRY [04.08.2019].

Peres, M. F. (2015). As minas e a agulheta: romance e história em As minas de prata, de José de Alencar. Belo Horizonte: Editora UFMG.

Schwarz, R. (2000). Ao vencedor as batatas. São Paulo: Editora 34. Recuperado de: $\underline{\text { https://bit.ly/3hpd9 } \mathrm{zv}}$ [03.04.2019].

Sommer, D. (2004). El mal de "María": (con)fusión en un romance nacional. En: Ficciones fundacionales: las novelas nacionales de América Latina (pp. 225-262). Bogotá: Ediciones Fondo de Cultura Económica. Recuperado de: https://bit.ly/2Y2g0qk [02.06.2018]. 